\title{
3D printing: can it make surgery more accessible?
}

\author{
Amos Nepacina Liew, GradDipSurgAnat ${ }^{1}$, Sean Ng Ying Kin, GradDipSurgAnat ${ }^{1}$, Jeremy F Khoo ${ }^{2}$ \\ ${ }^{1}$ Department of General Surgery, Monash Health, Victoria, Australia \\ ${ }^{2}$ Department of Breast Surgery, Monash Health, Victoria, Australia
}

Keywords: 3D printing; medical devices; surgical equipment; LMIC; accessible surgery

\begin{abstract}
The advancement of 3-Dimensional (3D) printing technology has made the design and production of items increasingly ubiquitous amongst the public. This technology is increasingly being used widely in various medical fields. With its increasing cost efficiency and accessibility, it is the author's perspective that $3 \mathrm{D}$ technology can improve accessibility to surgical procedures in low- and mediumincome countries (LMIC) by providing proceduralists with the basic equipment required to perform routine operations.
\end{abstract}

\section{Introduction}

Surgical services are increasingly recognised as an important component of public health [1]. These services remain widely accessible in developed countries. However, many fail to appreciate the disparity in low and middle-income countries (LMIC), with only $3.5 \%$ of operations performed on the poorest one-third of the world's population[2]. With the advent of accessible and high-quality 3-Dimensional (3D) printing that has been used in various medical fields [3], it is our view that $3 \mathrm{D}$ design and printing can help mitigate the shortage and cost of surgical resources in these communities.

\section{D printing technology}

3D printing is a manufacturing method that builds objects by the fusion or deposition of materials. The most common and widely used modality of printing available in medicine is Fused Deposition Modeling (FDM), with the cost of consumer-grade models upwards of USD 300 [4]. FDM printing utilises a heated nozzle to melt and release the plastic filament over a bed, building the object in layers as the plastic cools [5]. Most FDM printer models can print a variety of materials, including but not limited to Polylactic Acid (PLA), Acrylonitrile Butadiene Styrene (ABS) and Polyethylene Terephthalate Glycol (PETG) [all simples] (Table 1).

Correspondence: Amos Nepacina Liew

E-mail: liewamos@gmail.com

(i) https://orcid.org/0000-0002-4829-0495

Received: 21-10-2020 Accepted: 02-08-2021

DOI: http://doi.org/10.4038/sljs.v39i3.8752

\begin{tabular}{|l|l|l|l|}
\hline Material & Cost & Strength & Advantages \\
\hline PLA & $\begin{array}{l}\text { USD 10- } \\
40 / \mathrm{kg}\end{array}$ & $65 \mathrm{MPa}$ & Greatest ultimate strength \\
\hline ABS & $\begin{array}{l}\text { USD 10- } \\
40 / \mathrm{kg}\end{array}$ & $40 \mathrm{MPa}$ & $\begin{array}{l}\text { Heat resistant } \\
\text { Impact resistant } \\
\text { Durable }\end{array}$ \\
\hline PETG & $\begin{array}{l}\text { USD20- } \\
60 / \mathrm{kg}\end{array}$ & $53 \mathrm{MPa}$ & $\begin{array}{l}\text { Water resistant } \\
\text { Chemical resistant } \\
\text { Durable }\end{array}$ \\
\hline
\end{tabular}

Table 1. Characteristics of common materials used for 3D printing [6]

Equipment can be printed at approximately one-tenth the cost of their stainless steel equivalent [4].

The initial process of $3 \mathrm{D}$ printing requires the design of a Computer-Aided Design (CAD), a 3D rendered model of the object. There are many open-source and easy-to-use 3D software available for the design of CAD. Furthermore, many pre-made $\mathrm{CADs}$ are available for free online and require minimal modifications to fulfil a specific surgical need (e.g smaller retractors for paediatric cases). The CAD models are then uploaded into a printing software where it is reformatted and printed on the $3 \mathrm{D}$ printer.

$3 \mathrm{D}$ design and printing of surgical equipment has already been attempted and utilised on cadaveric inguinal hernia repair with success in 2017 [7]. Construction and modification of instruments, including a scalpel handle, haemostat, needle driver, forceps, self-retaining retractor, and Army-Navy retractors were done in a matter of days.

\section{Requirements}

Several key factors will facilitate a conducive 3D printing environment.

\section{(A) Environment}

A by-product of $3 \mathrm{D}$ printing is the aerosolisation of vapours from the printed material [8]. Fume hoods can be used to extricate the toxic fumes produced [8]. Materials for 3D printing should be kept in an airtight container with silica desiccant packets to prevent moisture absorption and material degradation during long term storage [9]. 


\section{(B) Electronic resources}

A reliable internet connection, suitable computer hardware and software are necessities. Adjustments can be made easily to existing models to be printed on-demand [6].

\section{Disadvantages of 3D printing Some disadvantages include: (A) Sterilisation}

Unlike stainless steel, sterilisation methods for plastic filaments remain limited. Currently, standardized autoclave sterilisation is not a feasible option for sterilisation of filament plastics as it might lead to warping and degradation of the material [10]. Limited research in sterilisation of 3D printing materials has shown that low-temperature hydrogen peroxide sterilisation or FDA approved glutaraldehyde protocol are the best methods, with minimal degradation and warping $[10,11]$. However, repeated sterilisation and durability of these materials have not been adequately researched, opening the potential for future development in durable materials.

\section{(B) Regulatory concerns}

3D printed medical devices are still subjected to regulatory requirements, with manufacturing regulations and the country's legal requirement being a barrier to production [12]. The FDA has guidelines available online regarding the governance of 3D printed equipment that can help mitigate certain barriers of production [13].

\section{Accessibility in LMIC}

Surgical equipment can be costly especially for health systems in LMIC. The start-up cost for 3D printing can range from USD 300 upwards for printers alone, with additional resources required for the purchase of a computer, printing materials and trained personnel. This confers the health institution the ability to customise individual equipment for specific operations and needs [14]. Once established, the actual manufacturing of $3 \mathrm{D}$ printed surgical equipment can be much cheaper than their stainless-steel counterparts. Given that the haemostat printed by George et al measures $8 \mathrm{~cm}$ by $4 \mathrm{~cm}$ by $0.5 \mathrm{~cm}(16 \mathrm{~cm} 3)$ [7], the cost of a 3D printed haemostat with current material prices (PETG at USD60/kg) can be as low as USD1. This is compared to the commercial price of titanium haemostat which can cost USD10 [15], making a 3D printed version 10 times cheaper than their commercial counterpart. Even factoring in additional costs such as electricity and wages, the manufacturing of a 3D printed device can be more cost-efficient than its branded counterpart. Ulmeanu et al manufactured a tracheostomy tube (factoring in parts and labour) for as low as 70 USD (62 Euros) when branded counterparts would normally cost significantly more [16]. However, this advantage may be diminished by a reduced number of times $3 \mathrm{D}$ printed instruments can be sterilised.
This technology is not just limited to the manufacturing of surgical equipment, 3D printing can be applied to other aspects of medicine including prosthetic and anatomic modelling. Hand prosthesis has been modelled for warwounded children for as low as USD 19 [17]. With technological advancement, the ability to customise individual prosthesis for patients can lead to improved postoperative outcomes and reduced complication rates. This can be seen in neurosurgery, where customised cranial plates can be printed to be fitted perfectly for patients who had a craniotomy [18].

Furthermore, the delivery of surgical instruments is a timely affair and can take months to be distributed to rural or remote hospitals. 3D printed instruments are cheaper and can be printed quickly, making them more accessible as compared to standard surgical equipment. Increased accessibility enables the population in these areas to receive appropriate and timely surgical care at a reduced cost.

\section{Conclusion}

The advancement of household 3D printing technology has benefited the medical community in various ways. With more research into materials and design, 3D printed surgical equipment has the potential to bridge the gap in low resource communities and make basic surgical procedures more accessible to these communities.

All authors disclose no conflict of interest. The study was conducted in accordance with the ethical standards of the relevant institutional or national ethics committee and the Helsinki Declaration of 1975, as revised in 2000.

\section{References}

1. Bae, J.Y., R.S. Groen, and A.L. Kushnes, Surgery as a public health intervention: common misconceptions versus the truth. Bull World Health Organ, 2011. 89(6): p. 395. https://doi.org/10.2471/BLT.11.088229

2. Weiser, T.G., et al., An estimation of the global volume of surgery : a modelling strategy based on available data. Lancet, 2008. 372(9633): p. 139-44.

https://doi.org/10.1016/S0140-6736(08)60878-8

3. Garcia, J., et al., 3D printing materials and their use in medical education: a review of current technology and trends for the future. BMJ Simul Technol Enhanc Learn, 2018. 4(1): p. 27-40 https://doi.org/10.1136/bmjstel-2017-000234

4. Rankin, T.M., et al..., 3D printing surgical instruments: Are we there yet? J Surg Res, 2015. 189(2): p. 193-197. https://doi.org/10.1016/j.jss.2014.02.020

5. Mertz, Dream it, design it, print it in 3-D: what can 3-D printing do for you? IEEE Pulse, 2013. 4(6): p. 15-21.

https://doi.org/10.1109/MPUL.2013.2279616

6. Simplify3D. Filament Properties Table. 2020; Available from: https://www.simplify 3 d.com/support/materialsguide/properties-table/. 
7. George, M., et al., Inguinal Hernia Repair Using 3D Printed Surgical Instruments in the Cadaveric Model: A Feasibility Study. Glob Surg, 2017.3(2).https://doi.org/10.15761/GOS.1000156

8. Randolph, S.A., 3D Printing: What Are the Hazards? Workplace Health Saf, 2018. 66(3):p. 164. https://doi.org/10.1177/2165079917750408

9. Schmied, C. 3D Printer Filament Storage: 8 Safe Ways to Store Filament. 2018; Available from: https://all3dp.com/2/filamentspool-8-ways-to-safely-store-your-filament/.

10.Oth, O., et al., How to Sterilize 3D Printed Objects for Surgical Use? An Evaluation of the Volumetric Deformation of 3DPrinted Genioplasty Guide in PLA and PETG after Sterilization by Low-Temperature Hydrogen Peroxide Gas Plasma. The Open Dentistry Journal, 2019. 14.

https://doi.org/10.2174/1874210601913010410

11.Athanasiou, K., G. Niederauer, and C. Agrawal, Sterilization, Toxicity, biocompatibility and clinical applications of polylactic acid/ polyglycolic acid copolymers. Biomaterials, 1996. 17: p. 93-102.

https://doi.org/10.1016/0142-9612(96)85754-1

12.Ursan, I.D., L. Chiu, and A. Pierce, Three-dimensional drug printing: a structured review. J Am Pharm Assoc (2003), 2013. 53(2): p. 136-44.

https://doi.org/10.1331/JAPhA.2013.12217
13.FDA. FDA's Role in 3D Printing. 2017; Available from: https://www.fda.gov/medical-devices/3d-printing-medicaldevices/fdas-role-3d-printing.

14. Culmone, C., G. Smit, and P. Breedveld, Additive manufacturing of medical instruments: A state-of-the-art review. Additive Manufacturing, 2019.27: p. 461-473.

https://doi.org/10.1016/j.addma.2019.03.015

15. Titanium Forceps General. 2021; Available from: https://www.medshop.com.au/products/titanium-forcepsgeneral?variant $=29486140325986 \&$ include_gst $=$ true\&gclid $=\mathrm{Cj}$ 0KCQjw0emHBhC1ARIsAL1QGNdCbDZdvKDQ1yEdd0Frk Cc1J_xMELxESvQ4HBCaUA14g0kExv41nykaAo6GEALw_w $\mathrm{cB}$.

16.Ulmeanu, M.E., et al., Comparative Evaluation of Optimum ADditive Manufacturing Technology to Fabricate Bespoke Medical Prototypes of Composite Materials. Materiale Plastice, 2015. 52: p. 416-422.

17.Cabibihan, J.J., et al., Suitability of the Openly Accessible 3D Printed Prosthetic Hands for War-Wounded Children. Front RobotAI, 2020. 7: p. 594196.

https://doi.org/10.3389/frobt.2020.594196

18.Ventola, C.L., Medical Applications for 3D Printing: Current and Projected Uses. PT, 2014.39(10): p. 704-11. 